\title{
Interferon- $\beta$ Is Less Effective Than Other Drugs in Controlling the Rate of Retinal Ganglion Cell Loss in MS
}

Yuyi You, MD, PhD, Michael H. Barnett, PhD, FRACP, Con Yiannikas, FRACP, John D.E. Parratt, FRACP, Jim G. Matthews, MStat, Stuart L. Graham, PhD, FRANZCO, and Alexander Klistorner, MD, PhD

Neurol Neuroimmunol Neuroinflamm 2021;8:e971. doi:10.1212/NXI.0000000000000971

\section{Abstract}

\section{Objective}

To investigate the association between disease-modifying therapies (DMTs) and the rate of progressive retinal ganglion cell (RGC) and nerve fiber loss in MS.

\section{Methods}

One hundred five relapsing-remitting patients with MS were followed annually for a median of 4.0 years using optical coherence tomography. Twenty-five healthy subjects were also included as normal controls. The rates of global peripapillary retinal nerve fiber layer ( $\mathrm{pRNFL}$ ), temporal RNFL (tRNFL), and ganglion cell inner plexiform layer (GCIPL) thinning were analyzed according to DMT type using a linear mixed-effects model. Optic radiation lesion volume was measured on brain MRI and included as a covariate to minimize the effects of retrograde transsynaptic degeneration.

\section{Results}

The annual rates of RNFL and GCIPL thinning were higher in patients treated with "platform" therapies (interferon- $\beta$ and glatiramer acetate) compared with DMTs of higher clinical efficacy (including fingolimod, dimethyl fumarate, natalizumab, alemtuzumab, rituximab, and ocrelizumab) (difference $=-0.22 \mu \mathrm{m} / \mathrm{y}, p=0.02$ for $\mathrm{pRNFL}$; difference $=-0.34 \mu \mathrm{m} / \mathrm{y}, p=0.009$ for tRNFL; and difference $=-0.16 \mu \mathrm{m} / \mathrm{y}, p=0.005$ for GCIPL). Based on an analysis of individual treatments (interferon- $\beta$, glatiramer acetate, fingolimod, and natalizumab), interferon- $\beta$ was associated with inferior RGC preservation, relative to the other drugs. No effect difference was found between glatiramer acetate, fingolimod, and natalizumab.

\section{Conclusions}

Progressive loss of RGCs in patients with MS is more pronounced in patients treated with interferon- $\beta$ than other DMTs. This finding may have implications for DMT selection in MS.

\section{Classification of Evidence}

This study provides Class IV evidence that for patients with MS, treatment with interferon- $\beta$ compared with other DMTs leads to a more pronounced rate of retinal ganglion cell loss.

\author{
Correspondence \\ Dr. You \\ yuyi.you@gmail.com
}

\section{MORE ONLINE}

$\rightarrow$ Class of Evidence

Criteria for rating therapeutic and diagnostic studies

NPub.org/coe 


\section{Glossary}

DMT = disease-modifying therapy; FLAIR = fluid attenuated inversion recovery; GCIPL = ganglion cell inner plexiform layer; LCVA = low contrast visual acuity; OCT = optical coherence tomography; ON = optic neuritis; $\mathbf{O R}=$ optic radiation; RGC = retinal ganglion cell; $\mathbf{p R N F L}=$ peripapillary RNFL; RNFL = retinal nerve fiber layer; $\mathbf{t R N F L}=$ temporal RNFL.

MS is recognized as a neurodegenerative disease with progressive neuroaxonal loss that begins in the earliest phases of the disease. Loss of retinal ganglion cells (RGCs) and their axons has been well documented in nonoptic neuritis (ON) eyes in MS. ${ }^{1}$ Based on a strong association between retinal nerve fiber layer (RNFL) and brain atrophy in patients with $\mathrm{MS},{ }^{2}$ loss of RGCs may reflect general neurodegeneration. Current disease-modifying therapies (DMTs) (including both platform therapies and DMTs of higher efficacy) are effective in suppressing neuroinflammation and reducing the rate of clinical relapses; however, their potential neuroprotective effects on axonal preservation are less well defined.

In the current study, we assessed the potential effect of current DMT on RGC loss in MS by analyzing the annualized rate of RNFL thinning with longitudinal optical coherence tomography (OCT) scans, referenced to treatment type. Optic radiation (OR) lesions were also examined annually during follow-up and included in the statistical model as a covariate to minimize the potential influence of retrograde transsynaptic degeneration. ${ }^{3}$ We first compared platform therapies (interferon- $\beta$ and glatiramer acetate) vs DMTs of higher efficacy, followed by analysis of the most frequently used individual drugs, such as interferon- $\beta$, glatiramer acetate, fingolimod, and natalizumab.

\section{Methods}

\section{Participants}

One hundred five consecutive relapsing-remitting patients with MS from 4 tertiary neuro-ophthalmology or neurology clinics in Sydney (Royal North Shore Hospital, Brain \& Mind Centre, Inner West Neurology, and the Save Sight Institute) were included in this study. MS was diagnosed according to the 2010 revised McDonald criteria. Exclusion criteria included acute $\mathrm{ON}$ within the previous 12 months and a history of other ocular or neurologic diseases. Only the patients who fulfilled the inclusion criteria were approached (determined by the referral neurologists). One ON patient with an episode of $\mathrm{ON}$ recurrence during the follow-up was excluded, and only the data collected before the relapse were used in analysis. Four patients were lost to follow up (only with the baseline measurements). All the other 105 participants with at least 1 follow-up visit are included in the current study. Patients were examined annually and followed for a median of 4.0 years (range 0.9-7.6). At each visit, the type of concurrent DMT was recorded. This study provides Class IV evidence on the effects of different DMTs on RGC and nerve fiber loss in relapsing-remitting MS. In addition, 25 healthy participants were recruited as controls.

\section{Standard Protocol Approvals, Registrations, and Patient Consents}

The study adhered to the tenets of the Declaration of Helsinki and was approved by the Human Research Ethics Committees of Macquarie University and the University of Sydney. Written consent was signed by all participants.

\section{OCT Imaging}

As described previously, ${ }^{4,5}$ RNFL and ganglion cell inner plexiform (GCIPL) thickness was measured with a Heidelberg Spectralis OCT (Heidelberg Engineering, Germany) according to the APOSTEL recommendations. ${ }^{6}$ OCT scans were performed under room light conditions without pupil dilation. The follow-up function was activated to ensure that longitudinal scans were obtained at the same locations. Both peripapillary ring (diameter $=3.5 \mathrm{~mm}$, for RNFL measurement) and macular radial pattern scans ( 6 slices in a star-like pattern, for GCIPL measurement) were inspected by 2 investigators (Y.Y. and A.K.) to ensure image quality according the OSCAR-IB criteria and to exclude segmentation errors.?

\section{MRI Scans and Measurement of OR Lesion Volumes}

Annual brain MRI scans were acquired on a GE MR750 3.0-T scanner with an 8-channel head coil as previously described ${ }^{3}$ using pre- and post-contrast (gadolinium) sagittal 3D T1, axial fluid attenuated inversion recovery (GE CUBE T2 FLAIR), and whole brain 64-directions diffusion-weighted imaging sequences. Probabilistic tractography was used to reconstruct OR fibers. Individual lesions were identified on coregistered T2 FLAIR images and semiautomatically segmented using JIM 7 software (Xinapse Systems, Essex, United Kingdom). Lesions were then intersected with OR fibers to obtain OR lesion volume measures.

\section{Statistical Analysis}

Statistical analysis was performed using SPSS (version 24.0; IBM Corp., Cary, NC) and Graphpad Prism (version 8.0; Graphpad, La Jolla, CA). Longitudinal OCT measures were obtained from both eyes in the study subjects and annualized RNFL change referenced to DMT type with a linear mixedeffects model that included OR lesion volume measures at each visit, age, sex, history of $\mathrm{ON}$, and disease duration as covariates. Patients who changed treatments during the follow-up were not excluded, and the intrasubject factor was taken into consideration when comparing the effects of different DMTs. As described previously, ${ }^{4}$ the model uses a multilevel structure with repeated measures nested within eye, nested within subjects. A $p$ value of less than 0.05 was considered statistically significant. 


\section{Data Availability}

The authors confirm that the data supporting the findings of this study are available within the article and from the corresponding author on reasonable request.

\section{Results}

Of the 105 patients with MS enrolled in the study, 51 had a history of ON. Demographic data of the study cohort are shown in table 1 . We first analyzed longitudinal RNFL and GCIPL changes in patients with MS vs healthy controls. We have previously shown that there is no difference between ON and non-ON eyes in the rate of RNFL/GCIPL thinning in the absolute thickness. ${ }^{4}$ In the current study, we again did not observe any difference in peripapillary RNFL (pRNFL; difference $=0.04 \mu \mathrm{m} / \mathrm{y}, 95 \% \mathrm{CI}-0.15$ to $0.24, p=0.65$ ), temporal RNFL (tRNFL; difference $=0.15 \mu \mathrm{m} / \mathrm{y}, 95 \% \mathrm{CI}-0.09$ to $0.40, p=0.22$ ), or GCIPL (difference $=0.02 \mu \mathrm{m} / \mathrm{y}, 95 \% \mathrm{CI}$ -0.08 to $0.13, p=0.70$ ) thinning between $\mathrm{ON}$ and non-ON eyes. Therefore, both $\mathrm{ON}$ and non-ON eyes were included in the current study. The rate of progressive retinal ganglion cell and fiber loss was faster in patients with MS compared with healthy control subjects (difference $=-0.19 \mu \mathrm{m} / \mathrm{y}[95 \% \mathrm{CI}$ $-0.39-0.01, p=0.07]$ for pRNFL; $-0.27 \mu \mathrm{m} / \mathrm{y}$ [95\% CI -0.51 to $-0.03, p=0.03]$ for tRNFL; $-0.16 \mu \mathrm{m} / \mathrm{y}$ [95\% CI -0.28 to $-0.04, p=0.01]$ for GCIPL), consistent with previous reports.

Table 1 Participant Characteristics at Baseline

\begin{tabular}{llll}
\hline & MS & Normal $^{\mathbf{a}}$ & $\boldsymbol{p}$ Value \\
\hline $\mathbf{n}$ & $105^{\mathrm{b}}$ & 25 & \\
\hline Age, $\mathbf{y}$ & $40.2 \pm 10.0$ & $38.8 \pm 10.7$ & $\mathrm{NS}$ \\
\hline Sex, M/F & $25 / 80$ & $7 / 18$ & $\mathrm{NS}$ \\
\hline Disease duration, $\mathbf{y}$ & $4(1-23)$ & $\mathrm{N} / \mathrm{A}$ & $\mathrm{N} / \mathrm{A}$ \\
\hline EDSS & $1(0-6)$ & $\mathrm{N} / \mathrm{A}$ & $\mathrm{N} / \mathrm{A}$ \\
\hline OCT, eyes & $\mathrm{n}=210$ & $\mathrm{n}=50$ & \\
\hline pRNFL & $89.2 \pm 12.8$ & $97.3 \pm 8.3$ & $<0.001$ \\
\hline tRNFL & $62.4 \pm 14.6$ & $73.4 \pm 12.5$ & $<0.001$ \\
\hline GCIPL & $56.6 \pm 5.6$ & $61.1 \pm 3.9$ & $<0.001$ \\
\hline OR lesion volume, $\mathbf{~ m m}^{\mathbf{3}}$ & $402(0-7,975)$ & $\mathrm{N} / \mathrm{A}$ & $\mathrm{N} / \mathrm{A}$ \\
\hline
\end{tabular}

Abbreviations: EDSS = Expanded Disability Status Scale; GCIPL = ganglion cell inner plexiform layer; N/A = not available; NS = not significant; OCT = optical coherence tomography; $\mathrm{OR}=$ optic radiation; $\mathrm{PRNFL}$ = peripapillary retinal nerve fiber layer; $\mathrm{TRNFL}=$ temporal RNFL.

Data are mean \pm SD or median (range).

Patients in the current study with a history of unilateral ON were also included in another study which has been reported previously. ${ }^{4}$ Patients on teriflunomide were excluded in the DMT group-based analysis due to inconsistent results regarding its clinical efficacy. ${ }^{16}$

a Part of the study cohort including normal subjects were previously described in another study investigating a different aspect of the disease.

${ }^{\mathrm{b}}$ Treatment at baseline included interferon- $\beta(n=24)$, glatiramer acetate $(n$ $=18)$, fingolimod $(n=25)$, teriflunomide $(n=6)$, dimethyl fumarate $(n=5)$, natalizumab $(n=15)$, alemtuzumab $(n=3)$, and not on any treatment $(n=9)$.

\section{Platform Therapies vs Higher Efficacy DMTs}

Next, we compared the rate of RNFL/GCIPL thinning in patients treated with platform therapies (interferon- $\beta$ and glatiramer acetate) vs DMTs of higher efficacy (including fingolimod, dimethyl fumarate, natalizumab, alemtuzumab, rituximab, and ocrelizumab). In the linear mixed effects model, which included OR lesion volume (plus age, sex, ON, and disease duration) as an additional cofactor, we found that retinal ganglion cell and fiber loss was faster in patients on the platform DMTs (difference $=-0.22 \mu \mathrm{m} / \mathrm{y}[95 \% \mathrm{CI}-0.42$ to $-0.03, p=0.02$ ] for pRNFL; $-0.34 \mu \mathrm{m} / \mathrm{y}$ [ $95 \% \mathrm{CI}-0.60$ to $-0.08, p=0.009]$ for tRNFL; $-0.16 \mu \mathrm{m} / \mathrm{y}$ [95\% CI: -0.27 to $-0.05, p=0.005]$ for GCIPL). The difference between the platform and higher efficacy DMTs remained significant after adjustment for the intervals between DMT initiation and OCT observation (difference $=-0.24 \mu \mathrm{m} / \mathrm{y}$ [95\% CI -0.43 to -0.04 , $p=0.02]$ for $\mathrm{pRNFL} ;-0.28 \mu \mathrm{m} / \mathrm{y}$ [95\% CI -0.52 to $-0.04, p=$ 0.02 ] for tRNFL; $-0.11 \mu \mathrm{m} / \mathrm{y}$ [ $95 \% \mathrm{CI}-0.22$ to $-0.01, p=$ 0.04] for GCIPL). Despite the fact that no patients showed macular edema on OCT during the follow-up, an additional sensitivity analysis was performed excluding the patients on fingolimod treatment. The difference between the platform and higher efficacy DMTs in GCIPL thinning remained significant (difference $=-0.18 \mu \mathrm{m} / \mathrm{y}, 95 \% \mathrm{CI}-0.34$ to $-0.02, p=0.02$ ).

Although some patients changed from platform therapies to DMTs of higher efficacy during the follow-up period, the slower progression rate on high efficacy treatments could not be simply explained by a carry-over drug effect or different disease staging. Nevertheless, to validate the above results, we performed a subanalysis by only including patients on the same DMT throughout the entire follow-up period $(n=71$ patients). The difference in OCT changes between the 2 DMT groups persisted (difference $=-0.28 \mu \mathrm{m} / \mathrm{y}$ [95\% CI -0.53 to $-0.04, p=0.02$ ] for pRNFL; $-0.25 \mu \mathrm{m} / \mathrm{y}$ [95\% CI -0.54 to $0.04, p=0.08]$ for tRNFL; $-0.24 \mu \mathrm{m} / \mathrm{y}$ [95\% CI -0.40 to $-0.08, p=0.003]$ for GCIPL) (the trend of projected OCT changes are demonstrated in figure).

\section{Analysis of Individual Drugs}

Interferon $\beta$, glatiramer acetate, fingolimod, and natalizumab were included in a further analysis to determine the effect of individual therapies. We only selected the drugs that had at least 100 OCT data points in the study cohort to ensure appropriate statistical power. Overall, patients showed faster rates of RNFL (mainly temporal) and GCIPL thinning when on interferon $\beta$ compared with the other 3 drugs. The results are summarized in table 2. No difference was found among glatiramer acetate, fingolimod, and natalizumab. This analysis suggests that the difference between the $2 \mathrm{DMT}$ groups described above is likely to be a result of the worse outcome of interferon $\beta$ on neuroaxonal preservation.

\section{Discussion}

This study provides evidence that the commonly used DMTs have a differential effect on the rate of progressive RGC loss in MS, a measure reflecting general neuroaxonal loss in the 

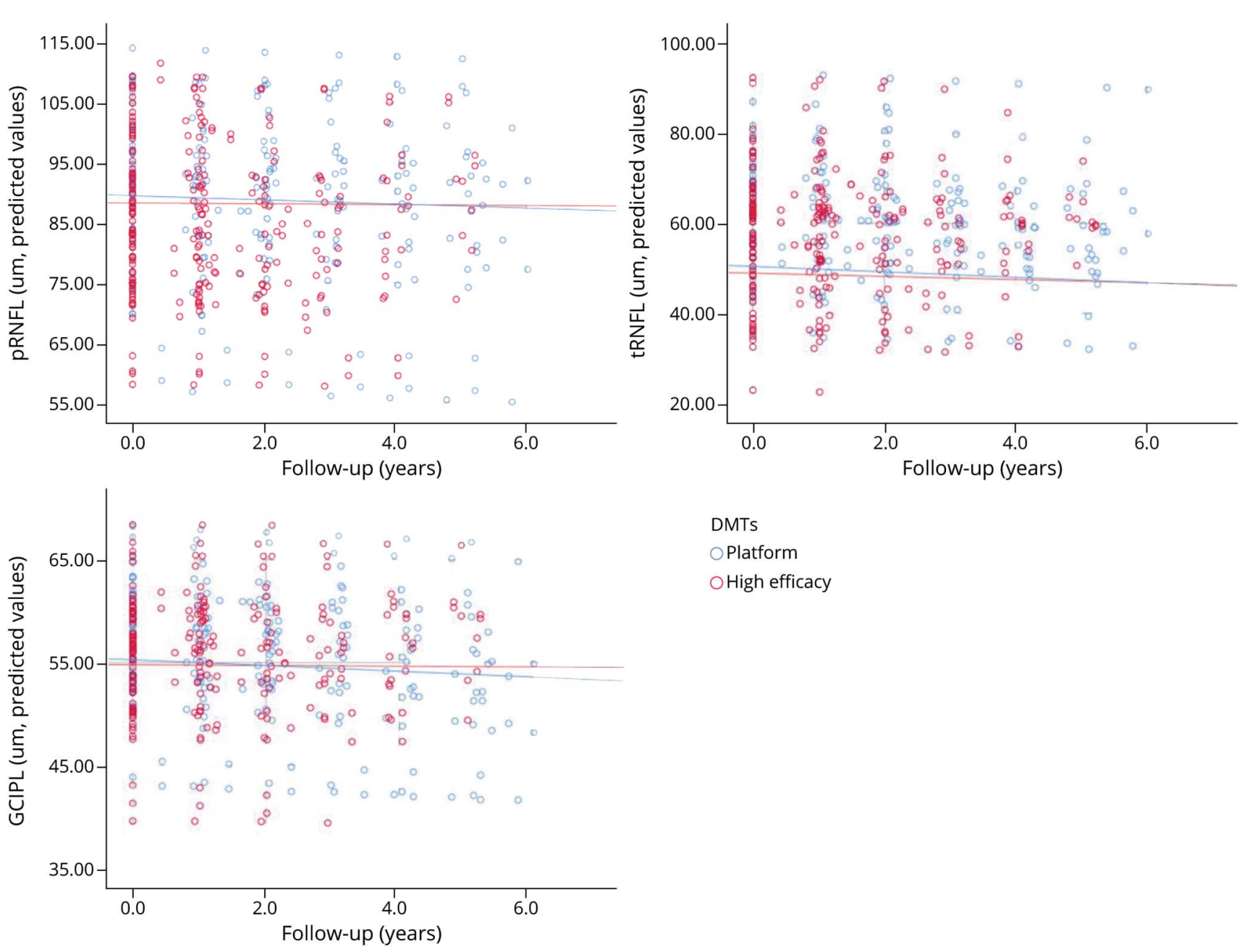

DMTs

OPlatform

OHigh efficacy

The baseline RNFL/GCIPL thickness was thinner in patients on the DMTs of higher efficacy (red lines), but patients on the platform therapies had a faster rate of thinning over the follow-up period (blue lines). DMT = disease-modifying therapy; GCIPL = ganglion cell inner plexiform layer; $\mathrm{pRNFL}=$ peripapillary RNFL; $\mathrm{RNFL}=$ retinal nerve fiber layer; $\mathrm{tRNFL}=$ temporal RNFL.

disease. It has not been well defined whether DMTs have any protective effects against RGC loss in MS. Knier et al. ${ }^{8}$ analyzed the association between longitudinal OCT changes and DMT treatment in patients with MS. The authors did not find any difference between with or without DMT (first-line) groups, but only 2 time points were analyzed in the study which could increase variability of results. Given the small sample size of patients with MS in our study who were not on any DMTs throughout the follow-up period $(\mathrm{n}=6)$, we were not able to perform a subanalysis with appropriate statistical power to compare the rate of RNFL/GCIPL thinning between untreated and treated patients. Future studies are needed to address this issue. The reported rate of annual progressive RNFL loss has been variable, between -0.36 and $-1.49 \mu \mathrm{m} / \mathrm{y}^{9}{ }^{9}$ This could be due to different scanning equipment/protocols and statistical methods (covariables) used. Concordant with the premise that earlier, aggressive use of immunotherapy can ameliorate longer-term neurodegeneration, we found that the use of higher efficacy therapies was associated with improved RGC preservation in patients with MS. Although it is generally accepted that modern oral and infusion therapies have better clinical efficacy compared with platform therapies ${ }^{10}$ and can help reduce the rate of retinal atrophy in relapsing-remitting $\mathrm{MS},{ }^{11} \mathrm{few}$ studies have directly compared the effects of 2 platform therapies. Our data suggest that glatiramer acetate has a greater neuroprotective effect, at least on RGCs, than interferon- $\beta$, which may have implications for DMT selection in early, relapsing disease. In support of this finding, a Cochrane metanalysis has shown both higher relapse rates and brain volume loss in patients treated with interferon- $\beta$ compared with glatiramer acetate. ${ }^{12}$

Some authors have previously investigated effects of DMTs on RNFL and GCIPL changes in MS. Knier et al. ${ }^{8}$ showed that retinal OCT changes are associated with disease activity. Although they did not reveal any difference between type of treatment on GCIPL thickness, only 2 time points were used 
Table 2 Comparisons Between Interferon $\beta$ and Other DMTs

\begin{tabular}{llll}
\hline Interferon $\boldsymbol{\beta}$ & Glatiramer & Fingolimod & Natalizumab \\
\hline PRNFL & NS & NS & NS \\
\hline tRNFL & $-0.54\left(-0.92 \text { to }-0.16, p=0.005^{*}\right)^{\mathrm{a}}$ & $-0.51(-0.86 \text { to }-0.16, p=0.004 *)^{\mathrm{b}}$ & $-0.57(-1.26 \text { to } 0.11, p=0.1)^{\mathrm{c}}$ \\
\hline GCIPL & $-0.21(-0.48 \text { to } 0.05, p=0.1)^{\mathrm{a}}$ & $-0.34(-0.46 \text { to }-0.21, p<0.001 *)^{\mathrm{b}}$ & $-0.35(-0.55 \text { to }-0.16, p=0.001 *)^{\mathrm{c}}$ \\
\hline
\end{tabular}

Abbreviations: DMT = disease-modifying therapy; GCIPL = ganglion cell inner plexiform layer; NS = not significant; OCT = optical coherence tomography; pRNFL = peripapillary retinal nerve fiber layer; $\mathrm{tRNFL}=$ temporal RNFL.

Data are difference $(95 \% \mathrm{Cl})(\mu \mathrm{m} / \mathrm{y})$. Significant $(p<0.05)$ and borderline $(p=0.05-0.1)$ differences are shown

After adjustment for the intervals between initiation of DMT and OCT observation: ${ }^{a}-0.49(-0.88$ to -0.11$), p=0.01$ for tRNFL; $-0.26(-0.52$ to 0.01$), p=0.06$ for GCIPL; ${ }^{b}-0.53(-0.87$ to -0.19$), p=0.03$ for tRNFL; $-0.33(-0.46$ to -0.20$), p<0.001$ for GCIPL; ${ }^{c}-0.55(-1.22$ to 0.13$), p=0.1$ for tRNFL; -0.40 ( $(-0.59$ to -0.21$), p<$ 0.001 for GCIPL.

* Differences persisted after $p$ value adjustment for control of the false discovery rate in multiple comparisons using the Benjamini-Hochberg approach.

in the analysis. In addition, combining interferon- $\beta$, glatiramer acetate, dimethyl fumarate, and teriflunomide as the first-line treatment may also limit the sensitivity of analysis. Although not compared with other DMTs, Zivadinov et al. ${ }^{13}$ suggested that glatiramer acetate may have a neuroprotective effect against RNFL loss. Furthermore, Button et al. ${ }^{14}$ showed that patients on both interferon- $\beta$ and glatiramer acetate had faster rates of GCIPL thinning compared with natalizumab. However, the fact that the difference was larger for subcutaneous interferon $(0.37 \mu \mathrm{m} / \mathrm{y})$ than for glatiramer acetate $(0.14 \mu \mathrm{m} / \mathrm{y})$ may also indicate that glatiramer acetate has slightly better protective effects compared with interferon $\beta$ in controlling RGC loss.

The small sample size remains a limitation of this study. We had to combine intermediate and high potency DMTs in the group-based analysis which limited our ability in assessing effects of all individual DMTs. Although we managed to perform the analysis of 4 most frequently used DMTs with sufficient OCT scans, the sample size for each individual drug was still relatively low, and in particular, we were not able to assess effects of high-dose high-frequency subcutaneous interferon $(\mathrm{n}=16)$ and low-dose low-frequency IM interferon $(\mathrm{n}=8)$ separately as described by Button et al. ${ }^{14}$ Therefore, the results of this study need further validation in future studies with larger sample size. Another limitation of the study is that we do not have a functional measure to support our conclusions. We could not find any difference in low contrast visual acuity (LCVA) changes between the treatment groups. This could be due to the fact that LCVA being a subjective test is already significantly impaired in ON eyes at baseline. In addition, reduction of LCVA is also likely to be associated with posterior visual pathway damage (e.g., OR lesions). These factors may potentially limit the sensitivity of LCVA in detecting subtle difference in the rate of RGC fiber loss over time in the current study design.

The mechanism of action that underpins the apparent neuroprotective effect of glatiramer acetate and higher efficacy therapies on RGCs is uncertain. Early use of high-efficacy therapy ameliorates long-term progression of MS disability and brain atrophy and is probably largely driven by the antiinflammatory properties of these agents. However, distinct neuroprotective effects cannot be excluded. Fingolimod, for example, has been shown to be neuroprotective for RGCs against glaucoma, ${ }^{15}$ a condition that is not traditionally considered a neuroinflammatory pathogenesis. Sphingosine-1phosphate receptors, which are bound by fingolimod, are also expressed on RGCs, potentially promoting their survival. Although the therapies studied here each have discrete mechanisms of action, suppression of inflammatory pathways represents is a common final endpoint and therefore remains a likely significant contributor to neuroprotection.

\section{Study Funding}

This study was supported by the National Multiple Sclerosis Society (NMSS) and National Health and Medical Research Council (NHMRC).

\section{Disclosure}

The authors report no disclosures relevant to the manuscript. Go to Neurology.org/NN for full disclosures.

\section{Publication History}

Received by Neurology: Neuroimmunology \& Neuroinflammation September 6, 2020. Accepted in final form December 21, 2020.

Appendix Authors

\begin{tabular}{lll}
\hline Name & Location & Contribution \\
\hline $\begin{array}{l}\text { Yuyi You, } \\
\text { MD, PhD }\end{array}$ & $\begin{array}{l}\text { Macquarie University, } \\
\text { Sydney, Australia }\end{array}$ & $\begin{array}{l}\text { Study design, acquisition of } \\
\text { data, analysis or } \\
\text { interpretation of data, } \\
\text { drafting/revising the } \\
\text { manuscript, and obtaining } \\
\text { funding }\end{array}$ \\
\hline $\begin{array}{l}\text { Michael H. } \\
\text { Barnett, } \\
\text { PhD, FRACP }\end{array}$ & $\begin{array}{l}\text { Brain and Mind Centre, } \\
\text { The University of Sydney, }\end{array}$ & $\begin{array}{l}\text { Acquisition of data and } \\
\text { drafting/revising the } \\
\text { manuscript }\end{array}$ \\
\hline $\begin{array}{l}\text { Con } \\
\text { Yiannikas, } \\
\text { FRACP }\end{array}$ & Royal North Shore & $\begin{array}{l}\text { Acquisition of data and } \\
\text { drafting/revising the } \\
\text { manuscript }\end{array}$ \\
\hline $\begin{array}{l}\text { John D.E. } \\
\text { Parratt, } \\
\text { FRACP }\end{array}$ & Royal North Shore & Acquisition of data \\
\hline
\end{tabular}

Continued 
Appendix (continued)

\begin{tabular}{lll}
\hline Name & Location & Contribution \\
\hline $\begin{array}{l}\text { Jim G. } \\
\text { Matthews, } \\
\text { MStat }\end{array}$ & $\begin{array}{l}\text { Sydney Informatics and } \\
\text { Data Science Hub, The } \\
\text { University of Sydney, } \\
\text { Australia }\end{array}$ & $\begin{array}{l}\text { Analysis or interpretation } \\
\text { of data }\end{array}$ \\
\hline $\begin{array}{l}\text { Stuart L. } \\
\text { Graham, } \\
\text { PhD, } \\
\text { FRANZCo }\end{array}$ & $\begin{array}{l}\text { Macquarie University, } \\
\text { Sydney, Australia }\end{array}$ & $\begin{array}{l}\text { Drafting/revising the } \\
\text { manuscript }\end{array}$ \\
\hline $\begin{array}{l}\text { Alexander } \\
\text { Klistorner, } \\
\text { MD, PhD }\end{array}$ & $\begin{array}{l}\text { Save Sight Institute, The } \\
\text { Aniversity of Sydney, }\end{array}$ & $\begin{array}{l}\text { Study design, analysis or } \\
\text { interpretation of data, } \\
\text { drafting/revising the } \\
\text { manuscript, and obtaining }\end{array}$ \\
& & $\begin{array}{l}\text { munding } \\
\text { fundia }\end{array}$ \\
\hline
\end{tabular}

\section{References}

1. Petzold A, de Boer JF, Schippling S, et al. Optical coherence tomography in multiple sclerosis: a systematic review and meta-analysis. Lancet Neurol 2010;9:921-932.

2. Gordon-Lipkin E, Chodkowski B, Reich DS, et al. Retinal nerve fiber layer is associated with brain atrophy in multiple sclerosis. Neurology 2007;69:1603-1609.

3. Klistorner A, Graham EC, Yiannikas C, et al. Progression of retinal ganglion cell loss in multiple sclerosis is associated with new lesions in the optic radiations. Eur J Neurol 2017;24:1392-1398.
4. You Y, Barnett MH, Yiannikas C, et al. Chronic demyelination exacerbates neuroaxonal loss in patients with MS with unilateral optic neuritis. Neurol Neuroimmunol Neuroinflamm 2020;7:e700. doi: 10.1212/NXI.0000000000000700.

5. Shen T, You Y, Arunachalam S, et al. Differing structural and functional patterns of optic nerve damage in multiple sclerosis and neuromyelitis optica spectrum disorder. Ophthalmology 2019;126:445-453.

6. Cruz-Herranz A, Balk LJ, Oberwahrenbrock T, et al. The APOSTEL recommendations for reporting quantitative optical coherence tomography studies. Neurology 2016;86:2303-2309.

7. Schippling S, Balk LJ, Costello F, et al. Quality control for retinal OCT in multiple sclerosis: validation of the OSCAR-IB criteria. Mult Scler 2015;21:163-170.

8. Knier B, Schmidt P, Aly L, et al. Retinal inner nuclear layer volume reflects response to immunotherapy in multiple sclerosis. Brain 2016;139:2855-2863.

9. Petzold A, Balcer LJ, Calabresi PA, et al. Retinal layer segmentation in multiple sclerosis: a systematic review and meta-analysis. Lancet Neurol 2017;16:797-812.

10. Brown JWL, Coles A, Horakova D, et al. Association of initial disease-modifying therapy with later conversion to secondary progressive multiple sclerosis. JAMA 2019; 321:175-187.

11. Sotirchos ES, Gonzalez Caldito N, Filippatou A, et al. Progressive multiple sclerosis is associated with faster and specific retinal layer atrophy. Ann Neurol 2020;87:885-896.

12. La Mantia L, Di Pietrantonj C, Rovaris M, et al. Interferons-beta versus glatiramer acetate for relapsing-remitting multiple sclerosis. Cochrane Database Syst Rev 2016; 11:CD009333.

13. Zivadinov R, Tavazzi E, Hagemeier J, et al. The effect of glatiramer acetate on retinal nerve fiber layer thickness in patients with relapsing-remitting multiple sclerosis: a longitudinal optical coherence tomography study. CNS Drugs 2018;32:763-770.

14. Button J, Al-Louzi O, Lang A, et al. Disease-modifying therapies modulate retina atrophy in multiple sclerosis: a retrospective study. Neurology 2017;88:525-532.

15. You Y, Gupta VK, Li JC, Al-Adawy N, Klistorner A, Graham SL. FTY720 protects retinal ganglion cells in experimental glaucoma. Invest Ophthalmol Vis Sci 2014;55: 3060-3066.

16. Laplaud DA, Casey R, Barbin L, et al. Comparative effectiveness of teriflunomide vs dimethyl fumarate in multiple sclerosis. Neurology 2019;93:e635-e646. 


\title{
Neurology \\ Neuroimmunology \& Neuroinflammation
}

\author{
Interferon- $\beta$ Is Less Effective Than Other Drugs in Controlling the Rate of Retinal \\ Ganglion Cell Loss in MS \\ Yuyi You, Michael H. Barnett, Con Yiannikas, et al. \\ Neurol Neuroimmunol Neuroinflamm 2021;8; \\ DOI 10.1212/NXI.0000000000000971
}

This information is current as of February 17, 2021

Updated Information \&

Services

References

Subspecialty Collections

Permissions \& Licensing

Reprints including high resolution figures, can be found at:

http://nn.neurology.org/content/8/3/e971.full.html

This article cites 16 articles, 2 of which you can access for free at: http://nn.neurology.org/content/8/3/e971.full.html\#\#ref-list-1

This article, along with others on similar topics, appears in the following collection(s):

All Imaging

http://nn.neurology.org//cgi/collection/all_imaging

Multiple sclerosis

http://nn.neurology.org//cgi/collection/multiple_sclerosis

Optic nerve

http://nn.neurology.org//cgi/collection/optic_nerve

Retina

http://nn.neurology.org//cgi/collection/retina

Information about reproducing this article in parts (figures,tables) or in its entirety can be found online at:

http://nn.neurology.org/misc/about.xhtml\#permissions

Information about ordering reprints can be found online:

http://nn.neurology.org/misc/addir.xhtml\#reprintsus

Neurol Neuroimmunol Neuroinflamm is an official journal of the American Academy of Neurology.

Published since April 2014, it is an open-access, online-only, continuous publication journal. Copyright

Copyright (C) 2021 The Author(s). Published by Wolters Kluwer Health, Inc. on behalf of the American

Academy of Neurology.. All rights reserved. Online ISSN: 2332-7812.

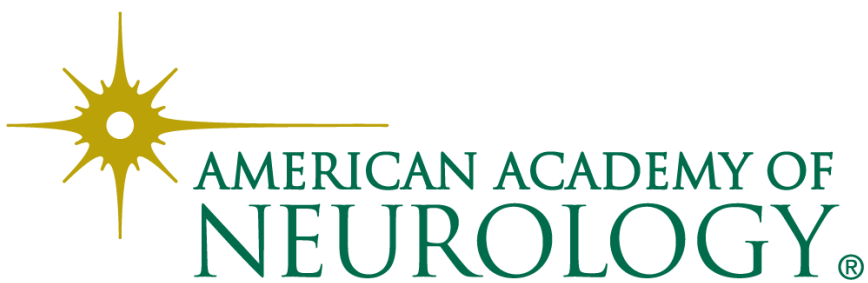

